\title{
Identity in the Modern Architecture of Kazakhstani Mosques: Ijtihad Principle
}

\author{
A.S. Galimzhanova ${ }^{1}$, M.B. Glaudinova ${ }^{1}$, Kh.Kh. Truspekova ${ }^{2}$, S.K. Karzhaubaeva ${ }^{3}$, S.E. Galimzhanov ${ }^{4}$ \\ ${ }^{1}$ Department of Architecture, International Education Corporation, Ryskulbekova St., 28 -050043, Almaty, \\ Republic of Kazakhstan.
}

${ }^{2}$ Department of History and Theory of Fine Arts, T. Zhurgenov Kazakh National Academy of Arts, Panfilova St., 127 -050000, Almaty, Republic of Kazakhstan.

${ }^{3}$ Department of Scenography, T. Zhurgenov Kazakh National Academy of Arts, Panfilova St., 127 - 050000, Almaty, Republic of Kazakhstan.

${ }^{4}$ Department of General Education, Pedagogy and Design, Eurasian Technological University, Tole Bi St., 109 -050000, Almaty, Republic of Kazakhstan.

\begin{abstract}
:
This article discusses traditions and innovations in the architecture and decor of Kazakhstani mosques in the context of globalization using the mosques of Nur-Sultan, Karaganda and Pavlodar as an example. It shows that architects and artists in their work, along with the tradition, must follow modern interpretive thought, the analogue of which is the Islamic concept - ijtihad. The hypothesis is that the modern architecture of Kazakhstani mosques is developing according to the principle of ijtihad - updating the tradition, which defines its originality and is a determining factor in its identity.
\end{abstract}

Keywords - Mosque Architecture, Kazakhstan, Identity, Ijtihad, Décor.

\section{INTRODUCTION}

From the very beginning, mosque architecture was a kind of experimental platform for the development of regional schools; therefore, it is distinguished by great stylistic pluralism. However, there are several canons that are the starting point of the creative search for the designers of the Muslim prayer building. The canons relate to the constituent parts of the mosque, such as zulla, sahn, and mihrab, which are of fundamental importance in its structure and image. Their mutual spatial arrangement determined several options for the composition of mosques in various Muslim regions. It is noteworthy that the stylistics of historical Kazakh mosques is generally characterized by a fairly casual approach to the choice of volumetric, spatial and figurative solutions. In this regard, of particular interest are the parallels between the modern period and the 19th century, when, after the final accession to the Russian Empire, Kazakhstan was included in the range of the influence of diverse architectural effects and creative movements.

There are two main volumetric and spatial solutions of the figurative structure of the temple - as a path (the influence of the European tradition) and as a center (the Muslim tradition).
The latter received numerous variations from a laconic cubic volume (the Aktas mosque) to a developed multi-domed vaulted structure, in which the mihrab part is distinguished by a dome of a larger height and diameter (the mosque of Kulsary village, the Sulikty complex, Duysenbai Dandygululy, etc.). It should be noted that the figurative solution of the spatially replicative structure of multi-domed mosques also reflects a deep layer of nomadic culture, in particular, correlated with the image of rhizome [1].

\section{RESULTS AND DISCUSSION}

II.I The centric composition of the temple as one of the fundamental codes of identity

Despite stylistic diversity, there is one common feature of Kazakh mosques, erected during the period of independence the universal compositional solution of the temple as a center [2]. The fundamental choice of the centric composition of the mosque, in our opinion, testifies to the reviving role of religion in modern Kazakhstani society and the new paradigm of an independent state, which returned the forgotten function of an environment-forming object to the cult object - a tradition characteristic of the religious architecture of Kazakhstan in the medieval period.

Currently, the typology of Kazakh mosques is undergoing changes: architects began to design mosques with two entrances (male and female), separate wardrobes, bathing rooms and prayer halls for women. Of particular importance is also the desire of the Spiritual Administration of Muslims of Kazakhstan to universalize mosque designs: standard mosque designs of different capacities are being developed. Traditional planning solutions are gradually being transformed, for example, the sahn courtyard in the city mosque is replaced by a small atrium or a light well. In addition, there is a volumetric and spatial development of the mosque's composition in vertical direction, as well as a transition from one level to two or three levels, with the installation of galleries for women. 
Based on a review of the architecture of mosques built in the late 20th and early 21st centuries in Kazakhstan, the following trends can be observed: 1) some mosques continued the tradition of Central Asian architecture, mainly in village and quarter mosques; 2) others combined the regional traditions of religious buildings of different countries; 3) the third, having absorbed the local traditions of applied, folklore and epic art, formed a completely different image of the mosque, while preserving the Muslim identity; 4) the fourth interpret the ideas of Islam in a new way, interpreting the universal ideas of fractality in architecture.

We believe that the second trend - a synthesis of regional traditions of different countries - is one of the most common in the modern religious architecture of Kazakhstan. Of greatest interest in this regard are the large cathedral mosques in Nur-Sultan, Shymkent, Karaganda and others. One of the most striking examples is the architecture of the Hazrat Sultan Mosque in Nur-Sultan designed for 5,000 people (architect S. Zhambulatov, construction company Sembol Insaat, 2012). It should be noted that the function of this mosque was expanded due to cultural and educational premises, a ritual room for wedding ceremonies and a number of other premises. The mosque complex is located on an area of more than 11 hectares, next to the Independence Palace and the Palace of Peace and Concord on the right bank of the Esil River. The total area of the building is 17.7 thousand square meters. The mosque building consists of three floors, where prayer halls, bathing and wedding ritual rooms, as well as halls for the Quran reading and educational classes are located. There is a wedding hall on the first floor, and there are prayer halls for men and women on the second and third floors (Fig. 1).

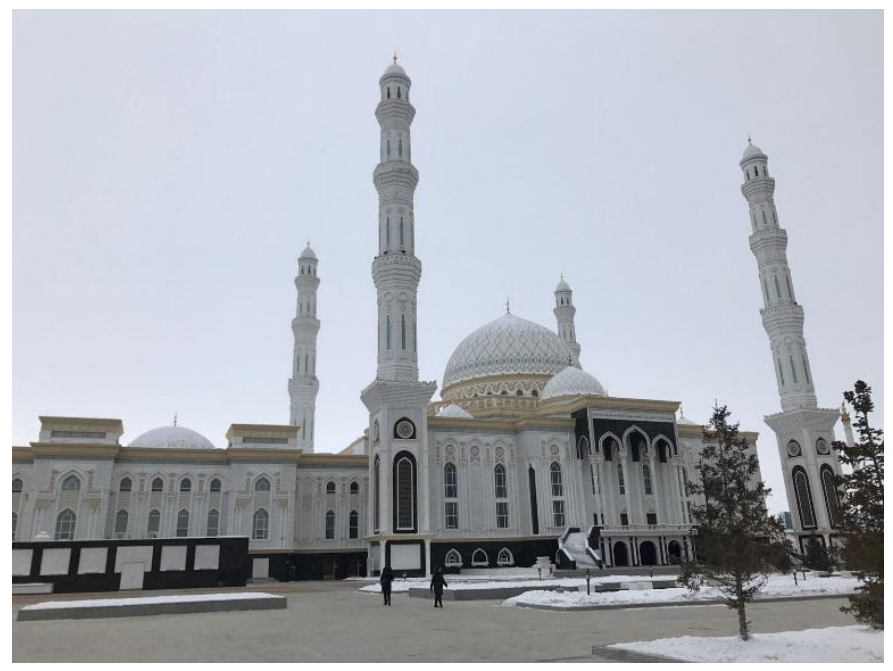

Fig. 1. A general view of the Hazrat Sultan Mosque

The volumetric and spatial solution of the Hazrat Sultan Mosque is an unfolding complex of premises along the main longitudinal axis of the entire mosque composition in the Qibla direction. On the same axis there is a consistent development of the mosque forms: from the main entrance portal, through the prayer halls, to the final large hall of the mosque with the mihrab. The building is crowned by the main dome of the mosque $(51 \mathrm{~m}$ in height and $28.1 \mathrm{~m}$ in diameter) and eight small domes $(10.45 \mathrm{~m}, 7.6 \mathrm{~m}$ in diameter; 33.46 , $25.25 \mathrm{~m}$ in height). The main dome of the mosque is placed on a monumental cylindrical drum. Four high minarets have a similar style to Arabian and Central Asian minarets, with a characteristic faceted trunk surface and tiers of decorative balconies. The height of each of the four minarets is $77 \mathrm{~m}$.

The Hazrat Sultan Mosque was built in the Islamic architectural tradition using the Kazakh ornament (Fig. 2). Its architecture shows an example of the interaction of different regional styles of Muslim countries, subordinated to the main idea of faith in the One God, Allah. The shape of iwans, columns, arches, and domes embraces the architectural context of the mosque. The surfaces of the walls, ceiling, and columns are decorated with Kazakh ornaments, with their patterns being organically woven into the elements of the order system. The color scheme of the mosque interior is based on the contrast of the minimalist, almost white, interiors of the halls and the polychrome mihrab paintings and domed spaces.

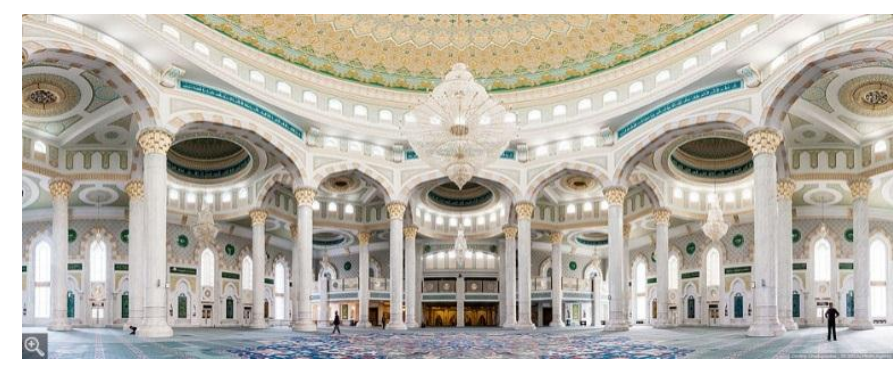

Fig. 2. The interior of the Hazrat Sultan Mosque

It should be noted that the compositional and stylistic techniques of the Hazrat Sultan Mosque have some analogues in Indian architecture of the Mughal period, as well as ancient Iran, Anatolia, Central Asia and Kazakhstan. The synthesis of Muslim architectural techniques is becoming the artistic language of the architecture of the main mosque of Kazakhstan. Architect S. Zhambulatov took an extremely subtle and delicate approach to the color scheme of the interior and exterior of the mosque, using the color of the summer steppe from pink to brown tones. He demonstrated the artist's intuition when using different textures of materials and choosing a rich palette of the matte shades of yellow, blue, brown and turquoise colors in the decoration of the mosque, which added nobility and grace to the style of the main cathedral mosque in Nur-Sultan. We believe that the best artistic achievement of the mosque was the solution of the main entrance portal with a harmonious combination of the shape, line and color of the decorative elements, inspired, in our opinion, by the architecture of Western Kazakhstan. It should be added that the Hazrat Sultan Mosque is a unique architectural structure also due to the fact that the architect was able to form a place around the mosque, where the "space of the spirit" opened to the urban space. The architect skillfully put the mosque into the cultural and urban planning context of Nur-Sultan, thereby allowing the mosque to be accessed not only by Muslims. The compositional and spatial solution of the Hazrat Sultan Mosque had a significant impact 
on the search for further architectural originality not only of the cathedral mosque (jami), but also of the district (mahalla) mosque in Kazakhstan.

\section{II.II The principle of Ijtihad and the globalization process in modern mosque architecture}

In modern architecture, it is important to resist the ideology of globalization, aimed at the formation of averaged, standardized ideas about values. The globalized nature of urban architecture is manifested, first of all, in high-tech buildings. For example, numerous shopping and entertainment centers, buildings of various corporations, holdings and banks made of "glass and concrete" are currently being built in the historical centers of large cities in Kazakhstan. The globalization pressure surely has some effect on the architecture of modern religious buildings, but this should be prevented, since the mosque is a spiritual guide between the past and the present. Therefore, today more than ever, the personality of the architect, as well as his or her responsibility, is of great importance.

We believe that the design of religious buildings requires modern architectural thought, and, therefore, interpretive and philosophizing thought. In this regard, we agree with Sh. Shukurov and R. Shukurov, who stated that "the whole history of Islamic culture shows that not a single problem of theologians was left without the attention of philosophers and, typically, poets, artists, and architects. Logical tafsir has always been balanced by poetic note and philosophical interpretation. The man of Islam is an interpreter" [3]. According to philosopher Mohammed Arkoun, as cited by Sh. Shukurov, architects should follow ijtihad in their work: "Ijtihad is also a struggle of tradition and innovation; it concerns all the major spheres of culture - from theology and jurisprudence to the problems of construction, if there's nothing about it stated in the Quran and the Sunnah of the Prophet. One more thing needs to be understood - ijtihad does not encroach on a fundamental change in the ummah foundations, we are talking about intricate innovations in a particular area of knowledge, and only educated people should use it" [3]. We agree with Mohammed Arkoun and S. Shukurov that the concept of ijtihad is relevant today and associated primarily with the problem of innovation in the architecture of modern mosques.

The architect and artist, using architectural harmonization means, creates his or her own idea of the universe in the context of the holy book Quran when designing new mosques. At the same time, the architect's creative intention is associated not only with the traditional values of Islam, but also with the totality of the phenomena of local ethnic culture. For example, the artists G. Yeshkenov and A. Zhamkhan, creating the decorative design of the mosques in Nur-Sultan, Almaty, Ust-Kamenogorsk, Kokshetau, Kyzyl-Orda, Pavlodar, and Taldykorgan, considered it legitimate to introduce the techniques of Kazakh applied art into the Islamic palette of interior decoration. The example of the Kazakh artists in this sense is indicative and follows the concept of ijtihad. Designing the mosque interiors, the artists came to the conclusion that the decorative design of religious buildings in Islamic countries is not uniform - they have strong signs of ethnic cultures. Therefore, they adopted an important strategy for their own creativity to follow the traditions of the Kazakh ornament in their work.

Analyzing the works of these masters, Kazakhstani art critic S.A. Shklyaeva notes their eclecticism: "In terms of the stylistic nature, the solutions of the mosque interiors and exteriors are eclectic (and this is the main sign of post-modern architecture) ..." [4]. Let us disagree with this statement. For this, we turn back to Sh. Shukurov, who explains that "the concept of ijtihad also extends to architecture. That is why Arkoun calls to change the old rhetoric, old syntax and semantics together with the theory of metaphor... Following Arkoun's thought, it is logical to think that the concept of ijtihad also extends to the architectural fabric of the renewed Muslim culture. After all, the above words were uttered by him among architects and for architects" [3]. We believe that the merit of the Kazakh artists G. Yeshkenov and A. Zhamkhan consists in the fact that they, based on the Islamic artistic tradition, created a new artistic language for the decor of Kazakhstani mosques using the Kazakh ornament, which best corresponded to the ethnocultural discourse of the Kazakhs.

One of the best examples of the color mosque scheme by the artists G. Yeshkenov and A. Zhamkhan is the Karaganda mosque interior (2011, Fig. 3 and Fig. 4). The lower part of the prayer hall is made in an ocher tone in combination with a greenish color. In the upper part of the wall, the color tone changes and gradually turns into turquoise, then in cyan and blue. With the help of the color, the artists showed the transition from earth to sky, thereby creating a special color harmony of the prayer space of the mosque. All the mosque interiors by G. Yeshkenov and A. Zhamkhan are created in the special aesthetics of the Garden of Eden - Firdaus. Thus, the decorative design of modern Kazakh mosques applies both the preservation of the tradition of Islamic mosques and the adherence to ijtihad, that is, the traditions that are being born today. "Tradition is not necessarily obsolete, nor is it synonymous with stagnation. Moreover, tradition should not relate exclusively to the distant past, on the contrary, it can be formed recently" [4].

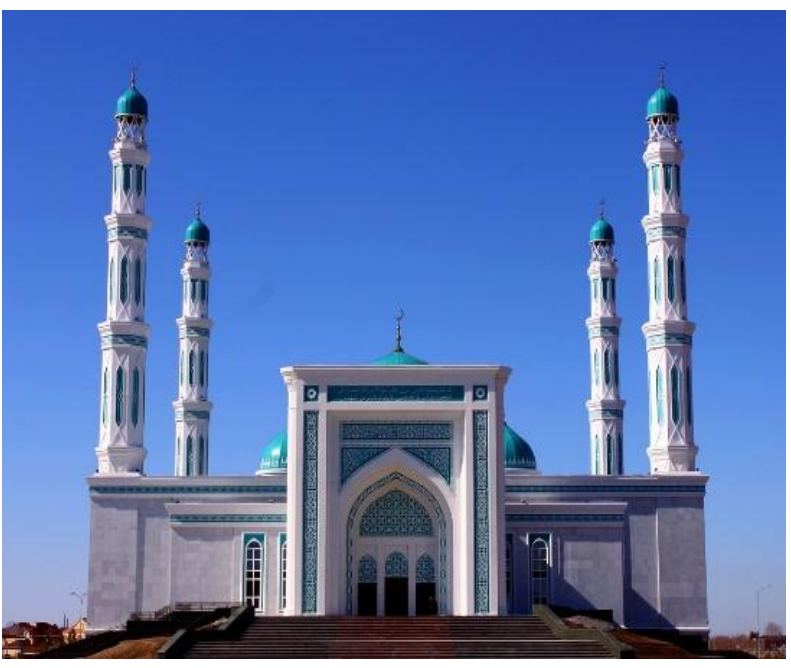

Fig. 3. A general view of the Karaganda mosque 


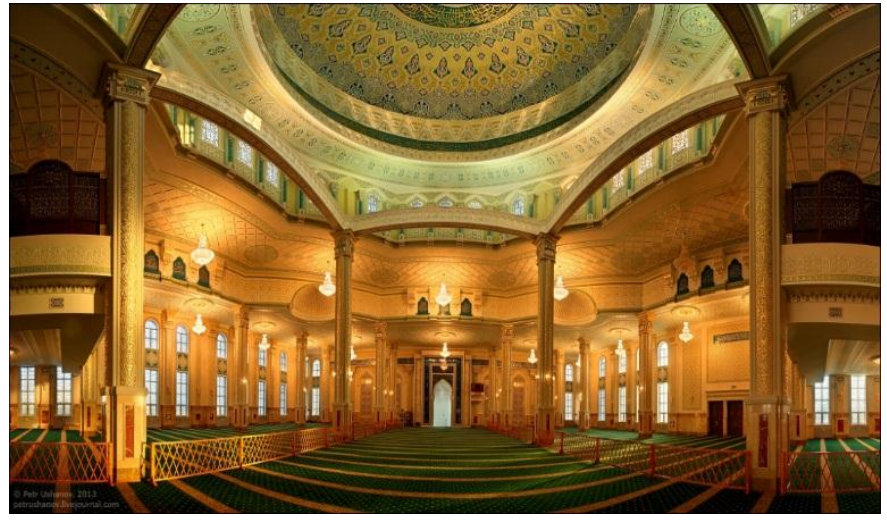

Fig. 4. The interior of the Karaganda mosque

\section{II.III New artistic tradition}

An example of the new artistic tradition is also the Mashkhur Zhusup Mosque in Pavlodar designed for 1,500 people (architect T. Abilda, 2001). The main volume of the mosque is represented by a huge corrugated cone of an emerald green color, which is crowned with a small dome and surrounded by four high minarets (64 m high). The conical shape of the mosque cover resembles the helmet of an epic batyr, and the surrounding minarets look like arrows (Fig. 5). We believe that the mosque image is metaphorical and associated not only with the shape of the helmets of heroes-batyrs of the great Kazakh epos "Koblandy", "Er-Targyn", "Er-Sain”, "Kambar", "Alpamys", who defended their people, but also with the architectural tradition of the cone-shaped domes of the BabajiKhatun (9th-10th centuries, Taraz) and Aisha-bibi (11th-12th, Taraz) mausoleums.

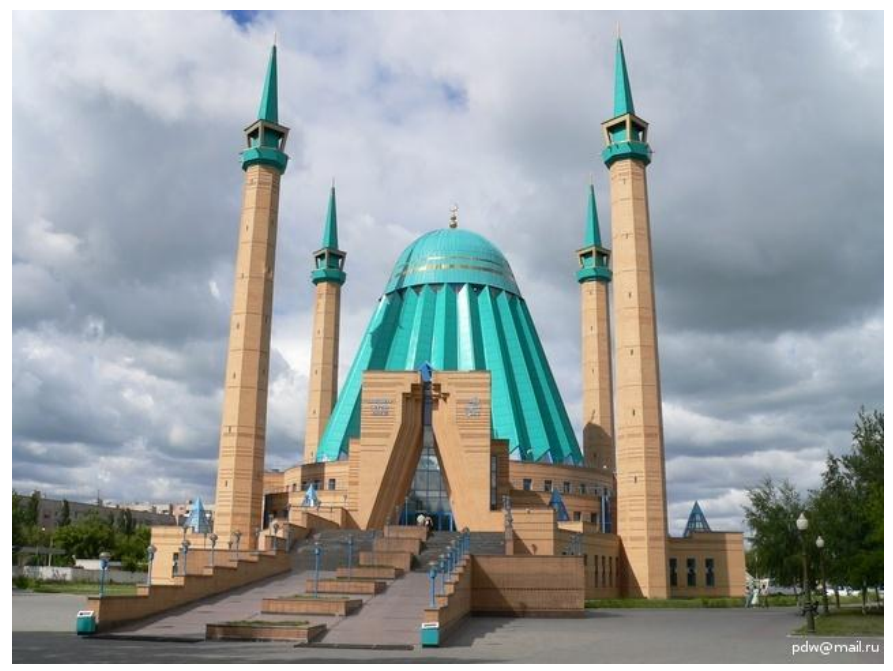

Fig. 5. A general view of the Mashkhur Zhusup Mosque in Pavlodar

Interpreting the shape of the mosque, one can assume that the architect, following the poet-zhyrau, resorted to a metaphor for the spiritual transformation of a person into a hero-batyr. In their song-poetic works, zhyrau philosophically interpreted life and in a poetic form explained various events in human life, giving advice to people on how to overcome difficult life moments. We believe that such an interpretation is justified and supported by the entire structure of the mosque [6]. The architecture of the mosque is directed upward and evokes the thought of a flight, both real and spiritual, as if the mosque is ready to take off. The height of the dome with a crescent is 54 $\mathrm{m}$, and the height inside the prayer hall is $33 \mathrm{~m}$. The prayer hall of the mosque, which has the outline of an eight-pointed star, is raised to a three-stage stylobate foundation. Most likely, it is this setting of the cone-shaped tent on a three-stage foundation that makes the architecture of the mosque soaring upward [7]. The main entrance to the mosque is located at the junction of two angles of the eight-pointed star, whose axis determines the direction of the quibla. The entrance is led by a ceremonial rising seven-flight staircase (more than $70 \mathrm{~m}$ wide) to the mark of the prayer hall $-4.95 \mathrm{~m}$.

The Mashkhur Zhusup Mosque in Pavlodar is a unique and innovative building in the architecture of Kazakhstan, representing the Mosque-Event. Its space-planning solution has no analogues in the architecture of Islamic mosques in Central Asia and was served as a model for the architecture of the central Bizhan Mosque in Shymkent (architect G. Sadyrbayev, 2014). The flattened cone-shaped tent of the prayer hall, formed by convex corrugations, is facilitated by vertical and horizontal glazing, creating the effect of lightness and emphasizing the centripetal composition of the entire object (Fig. 6 and Fig. 7). The lightness of the central dome shell is contrasted by the massive verticals of the minarets, whose three tiers of decreasing faceted foundations are sparingly cut by plane and perspective light openings. Unlike the Pavlodar mosque, dominated by the vertical axis (elongated dome proportions, sharp needles of thin minarets), the Shymkent mosque has squat shapes, which makes it possible to define the basic semantic prototype as the architecture of nomadic housing: there arise associations with huge festive yurts of the Mongolian and Kazakh nobility, in several tens of ropes, the images of which are preserved in Chinese and Persian sources [8-10].

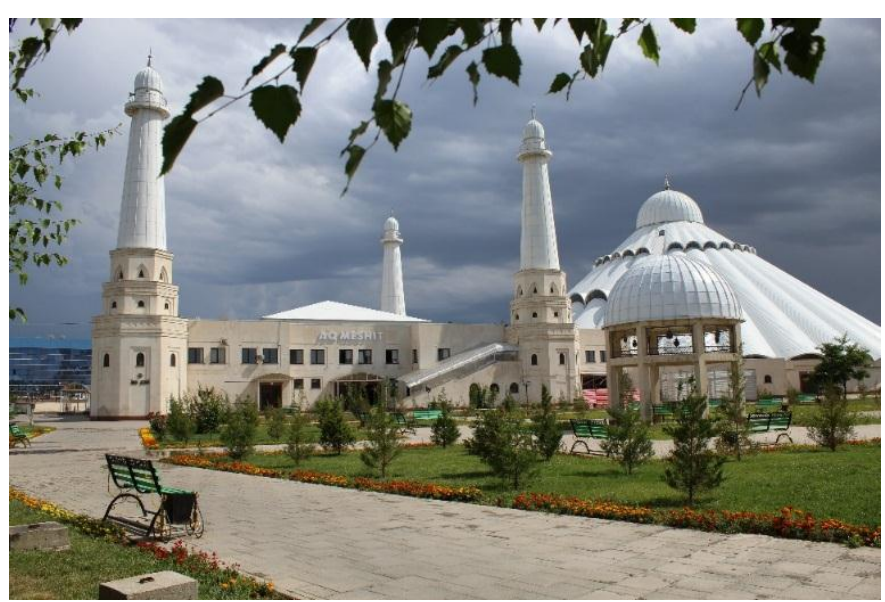

Fig. 6. A general view of the Bizhan Mosque in Shymkent 


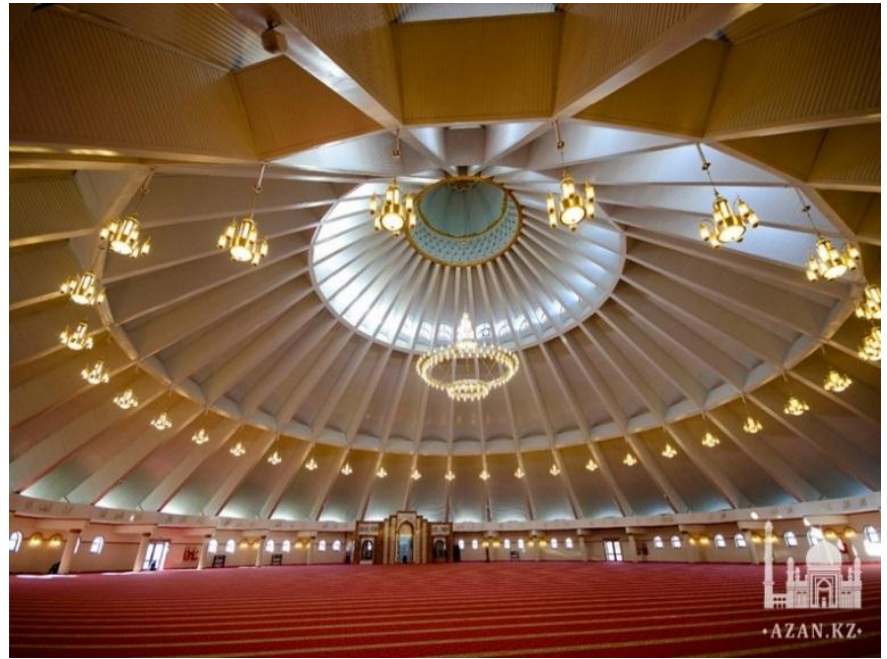

Fig. 7. The interior of the Bizhan Mosque in Shymkent

The urban development innovations of this building include the organization of the annular space of the regular park around the mosque, the alleys of which from all sides lead to the square formed around the mosque. On Fridays and holidays, "the procession of believers going up the grand staircase creates an unforgettable picture of either a religious demonstration, like around the Kaaba, or a fantastic landing of people on a ship flying to heaven. The "landing" of believers in the mosque from the center of the cathedral square is the main drama of the play, where the entire space around the mosque serves as a place for small actions - meetings, expectations, communication, spiritual unity, a sense of joyful holiday like the foreground in front of the main picture, in this case, the entrance to the prayer hall" [6].

A new interpretation of the mosque building was proposed in the architectural design of the Yryskeldy Kazhy Mosque in Nur-Sultan (architect S. Zhambulatov, 2018). The shape of a centric object, traditional for Kazakh mosques, is brought to the limit here: the structure of the building is formed by the intersection of octahedrons, decreasing vertically to the highest point of the object. Diagonal intersections are supported in the interior by vertical columns of two types: small and large, which combine one or more levels of multifaceted overlap (Fig. 8). The intersections of octagonal contours form narrow light openings that create bright light triangles in the interior. Fully designed in white, the mosque interior opens a new page in the development of modern religious architecture in Kazakhstan.

Nevertheless, the tradition has been preserved: the flat surfaces of the exterior walls and the inclined surfaces of the interior ceilings are covered with a restrained geometrical ornamental relief. One of the most interesting findings is the portal of the mihrab, which in its purest form interprets it as a door to another world. This effect is enhanced by the inner dome light, which further emphasized the role of the main element of the mosque as a border into another space. The traditional epigraphy is enclosed in a diagonal grid (paraphrase of kerege?) of the drum part of the central dome, and here the illumination also emphasizes the immateriality of the language of Muslim revelation. The general unified structure of the mosque's volume, in which there is no clear border between the walls and the ceiling, as well as the flow of the internal space created a harmonious unity of shape and image (Fig. 8 and Fig. 9).

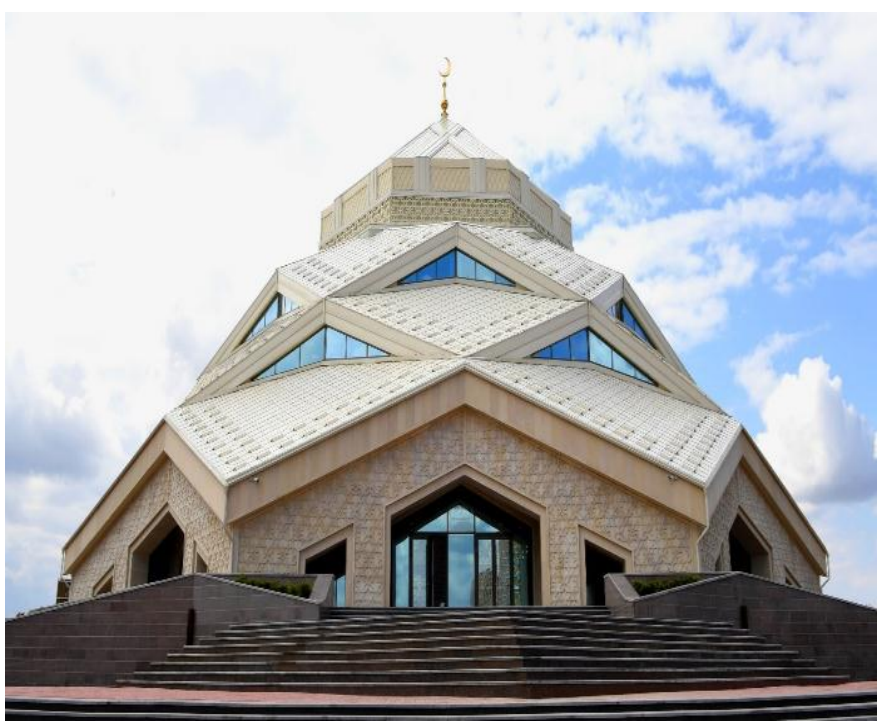

Fig. 8. A general view of the Yryskeldy Kazhy Mosque in Nur-Sultan

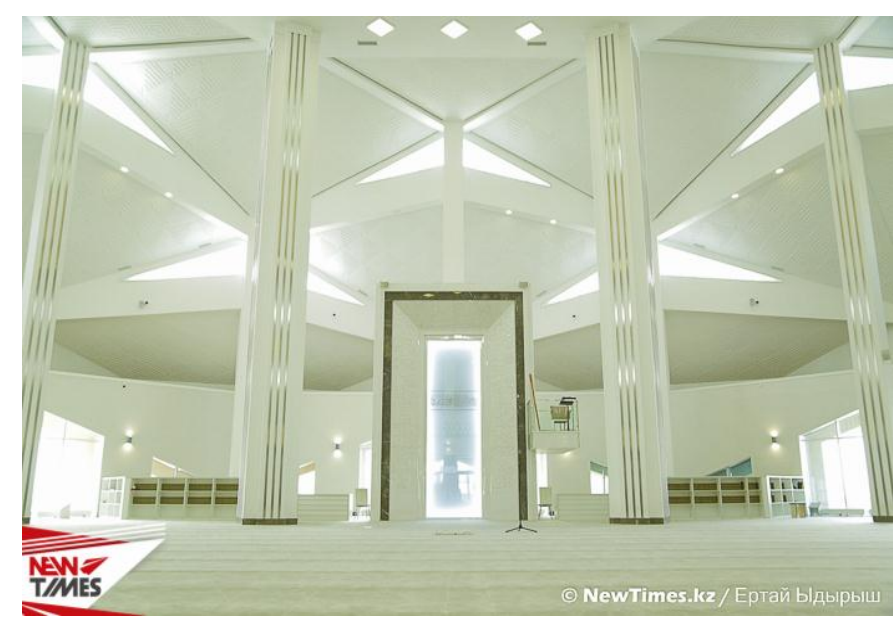

Fig. 9. The interior of the Yryskeldy Kazhy Mosque in NurSultan

This is one of the innovative Muslim buildings in Kazakhstan, in which the architect applied the techniques of geometry as the main formal and figurative expression of the idea of divine order and beauty. In this regard, the Yryskeldy Kazhy Mosque is undoubtedly traditional for Islam, since it is the arsenal of the universal language of geometry that is one of the main formation sources of Muslim art. We believe that this building is a vivid example of ijtihad in the modern religious architecture of Kazakhstan. In our opinion, this is a new interpretation of the technique of a multi-columned vaulted structure unfolding from the central dome, applied by architect S. Zhambulatov in the Hazrat Sultan Mosque. But the transition to a laconic geometrized language determined a completely new sound of the architectural form of the mosque. In addition, the architect used modern energy 
conservation principles, by including a religious object in the field of energy-intensive technologies, which means a new approach to the design of mosques in the Republic of Kazakhstan.

\section{CONCLUSIONS}

The architecture of the considered mosques indicates an extremely interesting and indicative, in terms of changing identity, process of transforming the structure and image of a religious object. The dynamic process, intended to serve as a bridge from the traditional past to the new future, indicates, in our opinion, a new stage in the development of the identity process in the architecture of Kazakhstan. At the same time, the ijtihad principle has been maintained: the traditional multidome structure with the flowing internal space has been preserved but developed by various means, which has led to a variety of compositional solutions for mosques. The transformation of the form is followed by corresponding changes in the decorative design of religious objects, which results in a new interpretation of the mosque building.

Therefore, we come to the conclusion that in order to create a modern artistic image of the mosque, Kazakh architects and artists use the following: (1) traditions of Central Asian architecture, mainly in village and quarter mosques; (2) regional traditions of religious buildings of Muslim countries (India, Turkey, Iran, Arab countries) in city cathedral mosques; (3) Kazakh traditions of applied, folklore and epic art, revealing a new image of the mosque, while maintaining the Muslim identity; (4) expansion of functions (premises of libraries, Islamic schools, museums of Islamic culture, wedding halls, funeral halls, video halls, etc. are being introduced); (5) Kazakh ornaments in the interiors of prayer halls and in the architectural elements of the interior and exterior; (6) a new approach in the urban planning context, when the mosque becomes an environment-forming dominant of the city or district and "opens" up to the space of the city.

\section{REFERENCES}

[1] Deleuze G, Guattari F. Rhizome. Paris, Minuit, 1976.

[2] Flier AYa. The birth of the temple: the experience of human self-determination in time. Culture of Culture Journal. 2020;1. http://www.cult-cult.ru/the-birth-of-thetemple-the-experience-of-human-self-determination-intime1/

[3] Shukurov Sh, Shukurov R. Time straightening. Otechestvennye Zapiski. 2003;5(14). http://www.stranaoz.ru/2003/5

[4] Shukurov ShM. Architectural fabric and architecture of a modern mosque. Iran-name, 2011;2:222-244.

[5] Shklyaeva SA. "Retrospective innovation" in the interior of the mosques of Kazakhstan (1991-2015). Central Asian Journal of Art Studies. 2016;1(1):37-49.

[6] Mergentay A, Kulov DB, Bekembayeva GS, Koikov VV, Omarkulov BK, Mussabekova SA. The analysis of working load of general practitioners in the Republic of Kazakhstan. Research Journal of Pharmacy and Technology. 2019; 12(5), 2283-2288.

[7] Kookueva VV. Trends of financing sustainable development of rural areas in Russia. Life Science Journal. 2014;11(6s):310-314. http://www.lifesciencesite.com/lsj/life1106s/062_24257li fe1106s14_310_314.pdf

[8] Kisamedin GM. The soaring central Mashkhur Zhusup Mosque in Pavlodar for 1,500 places in 2001. Bulletin of KazGASA. 2012;3-4:197-204.

[9] Glaudinova MB. To the problem of identity in the modern architecture of Kazakhstan. Proceeding of the International Scientific and Practical Conference "Issues of Art Criticism of the 20th and early 21st centuries". Almaty, 2016, pp. 120-123.

[10] Tussupbekova M, Bakenova R, Stabayeva L, Imanbayeva G, Nygyzbayeva R, Mussabekova S, Tayzhanova D. Clinic-Morphologic and Morphometric Criteria for Differential Diagnosis of Sarcoidosis and Pulmonary Tuberculosis. Open Access Macedonian Journal of Medical Sciences. 2019;7(9):1480-1485. 